\title{
To Go or Not to Go: Exploring Brain Activation During Response Inhibition Reading Tasks
}

\author{
Julia Craig ${ }^{1}$, Amberley V. Ostevik, MSc${ }^{2}$, Lindsey Westover, $\mathrm{PhD}^{2,5}$, Bill \\ Hodgetts, $\mathrm{PhD}^{2,3}$, Jacqueline Cummine, $\mathrm{PhD}^{2,4}$ \\ ${ }^{1}$ Faculty of Science, University of Alberta, Edmonton, Alberta \\ ${ }^{2}$ Faculty of Rehabilitation Medicine, University of Alberta, Edmonton, Alberta \\ ${ }^{3}$ Institute for Reconstructive Sciences in Medicine, Covenant Health, Edmonton Alberta \\ ${ }^{4}$ Neuroscience and Mental Health Institute, University of Alberta, Edmonton, Alberta \\ ${ }^{5}$ Department of Mechanical Engineering, University of Alberta, Edmonton, Alberta \\ Corresponding author: jacraig@ualberta.ca
}

\section{ABSTRACT}

Objective: Response inhibition is an understudied component of reading that aids in the selection of appropriate responses amidst complicated tasks. Our objective was to explore the contribution of brain regions associated with response inhibition processing in reading tasks that vary in difficulty of response inhibition.

Method: Participants $(\mathrm{N}=15)$ completed two go/no-go reading tasks while in a functional magnetic resonance imaging ( $\mathrm{fMRI}$ ) scanner, with the instructions to "name aloud the letter strings that spell a real word." For the minimal response inhibition condition, the foils, which are stimuli that should not be repsonded to, were nonwords with unfamiliar spelling and sound (e.g., "bink"). For the maximal response inhibition condition, the foils were pseudohomophones with unfamiliar spelling but familiar sound (e.g., "pynt"). The following brain regions associated with decision-making processes were analyzed: the anterior cingulate cortex (ACC), the dorsomedial prefrontal cortex (DMPFC), the inferior frontal gyrus (IFG), the middle temporal gyrus (MTG), the middle occipital gyrus (MOG), and the posterior insula (PI).

Results: Significant differences in activation within the nonword task were found for the DMPFC and the PI (the ACC approached significance). Significant differences in activation within the pseudohomophone task were found for the ACC, the MTG, and the PI. The IFG was found to be greatly activated for all words that had familiar phonemes (sounds). The MOG was found to be activated across all tasks.

Conclusion: We provide evidence for differential response inhibition processing in the decision-making network during reading tasks. This work is a necessary step in better understanding response inhibition ability for individuals with and without reading impairments.

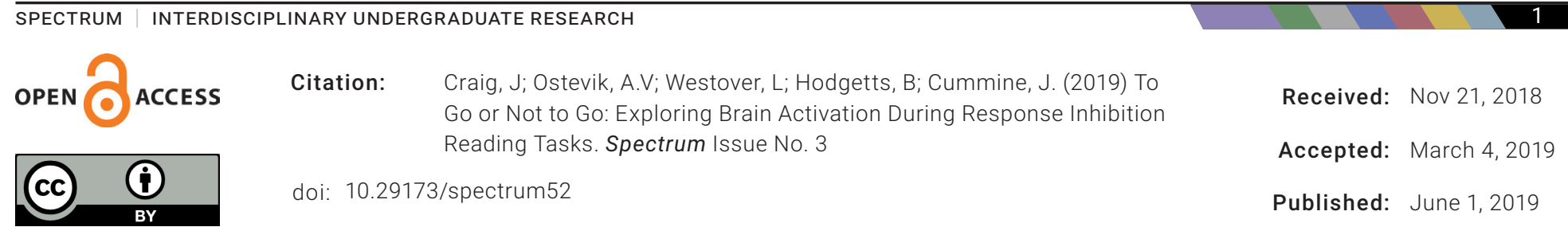




\section{Introduction}

Decision-making can be divided into two categories: autonomic processes and executive processes (Kahneman, 2003). Autonomic processes are those that are innate and reflexive, whereas executive processes are those that are effortful and conscious. A subdivision of executive processes is response inhibition (Stevens et al., 2015), which plays an important role in various reading tasks (e.g., go/no-go; Cummine, Aalto, Ostevik, Cheema, \& Hodgetts, 2018). For example, the pronunciation of exception words like "yacht" requires the inhibition of usual language processes that would cause you to pronounce the word /jæt/t/ (to rhyme with "patched"), and instead requires retrieval from stored internal vocabulary for the correct pronunciation, /jat/ (to rhyme with "caught"). The objective of this project was to explore the extent to which brain regions associated with decision-making processes are activated during reading tasks varying in response inhibition difficulty. It is hypothesized that brain regions involved in decision-making will be differentially activated during reading tasks varying in response inhibition difficulty.

\subsection{Response Inhibition}

Response inhibition is the ability to suppress a preponent (i.e., natural or habitual) behaviour or action (Li, Huang, Constable, Sinha, 2006). Response inhibition allows for the selection of appropriate responses amidst complicated situations and/or foils. One of the more commonly-used approaches to assess response inhibition is through the use of go/no-go or stop-signal tasks (Li et al., 2006). A participant may be presented with multiple go signals that are then followed by intermittent nogo (stop) signals which measure a participant's ability to quickly inhibit a task. Interest in investigating response inhibition stems from its association with many neurological conditions. For example, impaired response inhibition has been found in individuals with attention deficit hyperactivity disorder (ADHD; Aron \& Poldrack, 2005) and has also been used extensively in the reading literature (e.g., regularity effects-see section 1.3; Cummine et al., 2018; 2011). In the imaging space, several brain regions have been implicated as playing a marked role in response inhibition. For example, the anterior cingulate cortex has been reported to be involved in response selection (Botvinick, 2007) and the dorsomedial prefrontal cortex involved in error detection (Holroyd, Yeung, Coles, \& Cohen, 2005; Modirrousta \& Fellows, 2008) (see Figure 1). The extent to which specific inhibition effects are evident at the neural level during reading is not well understood.

\subsection{Reading}

The dual route model of reading proposes that there are two pathways that work together to aid in reading: the sublexical and lexical pathways (Coltheart, Rastle, Perry, Langdon, \& Ziegler, 2001) ${ }^{1}$. The lexical pathway is primarily used for the reading of familiar words; it requires retrieval from an individual's stored internal vocabulary, that is, their lexicon. For example, exception words (e.g., "yacht") and regular words (e.g., "hat") rely on the lexical pathway to be read correctly. The sublexical pathway is primarily used for reading unfamiliar words; it requires an individual to use their knowledge of graphemes (the smallest meaningful contrastive unit in a writing system) and phonemes (perceptually distinct units of sound) to decode the unknown letter strings. Stimuli that rely on the sublexical pathway include nonwords, such as "bint," and pseudohomophones (PHP), such as "pynt" which have unfamiliar spelling yet familiar sound. The lexical pathway, being dependent on the retrieval of known or familiar words, is more automatic, whereas the sublexical pathway, being dependent upon decoding unknown/unfamiliar words, requires higher level cognitive processes. Overall, several brain regions have been associated with the general basic reading and speech processes, including the inferior frontal gyrus (production; Guenther, 2006), posterior insula (phoneme processes; Oh et al., 
2014), middle temporal gyrus (meaning processes; Davey et al., 2016) and middle occipital gyrus (print processing; Vorobyev et al., 2004) (Figure 1)

\subsection{Response Inhibition and Reading}

The role of response inhibition has been studied in different capacities. One example is the regularity effect, which is the finding that words with typical spelling-to-sound correspondence (i.e., regular words) are read aloud more quickly than words with an atypical spelling-to-sound correspondence (i.e., exception words) (Hino \& Lupker 1998, 2000; Cummine, Amyotte, Pancheshen, \& Chouinard, 2011; Cummine et al., 2013). This finding has been taken as evidence for the additional response inhibition that is needed for exception words. Exception words are stimuli that produce two competing responses (e.g., /jæt/t/ and/jat/ for the word /yacht/). An additional example of the ways in which response inhibition has been studied is the modulation of task difficulty. Researchers have explored how response selection and inhibition change as a task goes from relatively easy (i.e., reliance on the lexical pathway-press " 1 " if the word spells a real word) to relatively hard (i.e., reliance on both lexical and sublexical pathways-press "1" if the word sounds like a real word). However, the extent to which such response inhibition processes are evident from brain region activation, when an individual is reading, has not been well established.

\subsection{Summary}

Response inhibition is an executive process that is commonly studied through go/no-go stop signal tasks (refer to 1.1). Response inhibition has been shown to be important for reading, yet it is still not well understood at the level of the brain. Furthermore, the exact brain regions responsible for response inhibition reading tasks are not clear (refer to 1.3). This investigation will compare brain activation across low complexity to high complexity (refer to 1.2) response inhibition reading tasks. This will contribute towards establishing a more comprehensive understanding of the brain regions required for response inhibition reading tasks.
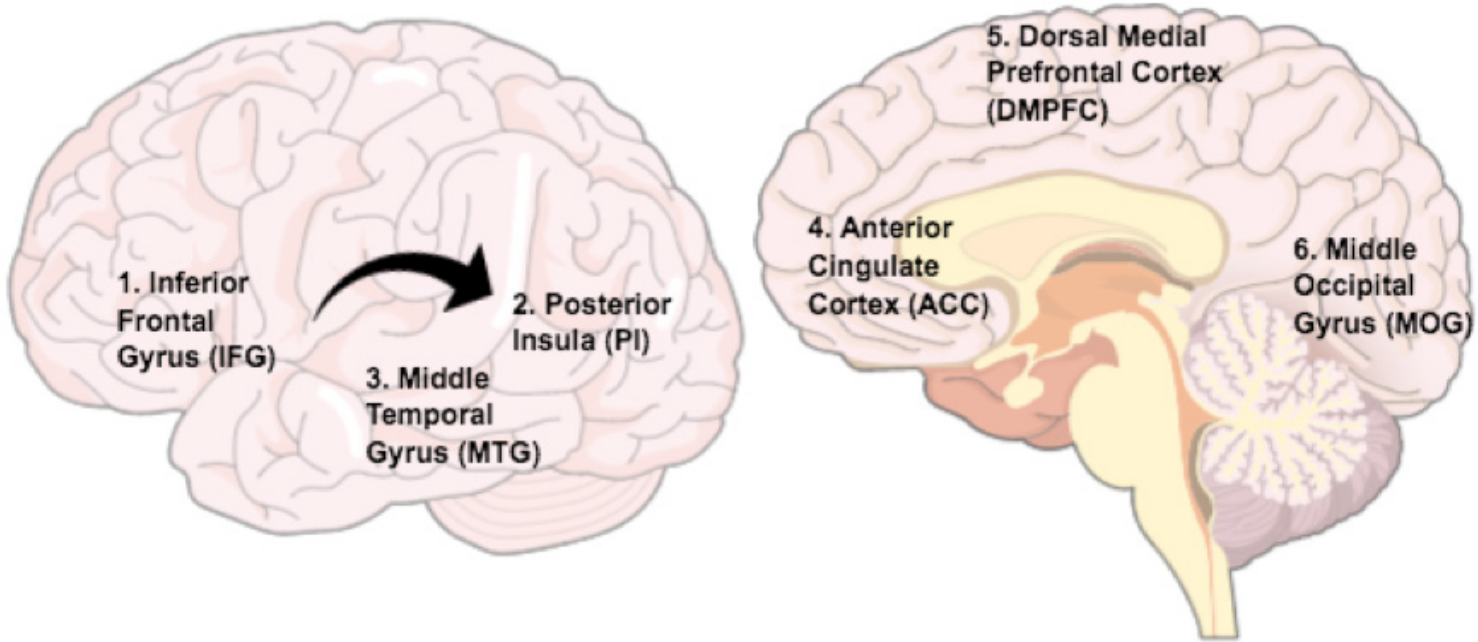

Figure 1. Visual representation of brain regions involved in decision-making processes and reading.

1. IFG - phonological processing; storing familiar speech sounds (Burton, 2001; Guenther, 2006)

2. PI - speech and articulatory production (Oh et al., 2014)

3. MTG - semantic control (Davey et al., 2016)

4. $\quad$ ACC - response selection (Botvinick, 2007)

5. $\quad$ DMPFC - error detection (Holroyd et al., 2005)

6. MOG - visual word form processing (Vorobyev et al., 2004) 


\section{Methodology}

This study was conducted as part of a larger study (see Cummine et al., 2018). Participants included fifteen university students (7 female; 8 male) who were recruited through responses to online advertisements and posters. Participants ranged in age from 18 to 22 years (Mean=19.73; $S D= \pm 1.33$ ) and 13 were right-handed. Criteria for including participants in the study consisted of normal or corrected-to-normal vision and English as a first language. Consent was obtained according to the ethical principles of the Declaration of Helsinki (2013, https://www.wma.net/policies-post/wmadeclaration-of-helsinki-ethical-principles-formedical-research-involving-human-subjects/). The experiment was performed in compliance with the relevant laws and institutional guidelines, and approval was obtained from the University of Alberta Health Research Ethics Board. All participants were paid a $\$ 30$ honorarium.

\subsection{Materials}

The stimuli consisted of 200 high and low frequency real words (e.g., regular and exception words; see Appendix 1). Stimuli that should not be responded to, also called foils, included 50 nonwords (e.g., "norve") and 50 pseudohomophones (e.g., "whyle"). Nonword foils were created by changing one or two letters of the real words and the pseudohomophones were compiled from current literature (e.g., Cummine et al., 2011). All stimuli were matched for onset phoneme (initial word sound), length, bigram sum (frequency of two adjacent letters), frequency (in the case of the real words), phonological neighborhood (sets of words that differ by a single sound), and orthographic neighborhood (words of the same length that differ by only one letter) (see Balota et al., 2007). The words were presented in two different lists: mixed with non-words (words mixed in with nonword foils; total=150), and mixed with pseudohomophones (words mixed in with pseudohomophone foils; total=150). Participants were instructed to read aloud only those words that spelled a real word, and to remain silent when they saw a nonword or pseudohomophone.

In the minimal response inhibition condition, the foils were nonwords (unfamiliar spelling and sound, e.g., "bink"). These foils represented a less complex response inhibition task because accuracy only required recognition of familiar words (i.e., real words; refer to section 1.2) and no response for unfamiliar words (i.e., nonwords). In the maximal response inhibition condition, the foils were pseudohomophones (unfamiliar spelling with familiar sound, e.g., "pynt"). This foil represents a more complex response inhibition task, because it requires differentiating words with familiar spelling and sound from pseudohomophones, which only have familiar sound. In order to be accurate for this foil, participants must decode the PHP (refer to 1.2) and then inhibit a response because PHPs have incorrect spelling.

\subsection{Procedure}

Participants came to the neuroimaging centre, which is located on the University of Alberta campus, where the Magnetic Resonance Imaging (MRI) technician ensured they could safely take part in the study (i.e., no contraindications to go in the MR scanner). Prior to going into the MRI scanner, participants were provided with information about the nature of the tasks they would be completing. Stimuli were presented using a data projector connected to the computer running E-Prime software (Psychology Software Tools, Inc., http://www.pstnet.com). For each condition an event-related design was used. An event-related design is a technique whereby changes in $\mathrm{fMRI}$ signal are measured in response to events. The events, (i.e., words and foils, including nonwords and pseudohomophones) were randomly presented with a fixation cross in between each word trial (Figure 2). Overt responses (e.g., speech) were recorded via an MR safe microphone placed approximately six inches from the participant's mouth. Images were acquired on a $1.5 \mathrm{~T}$ Siemens 


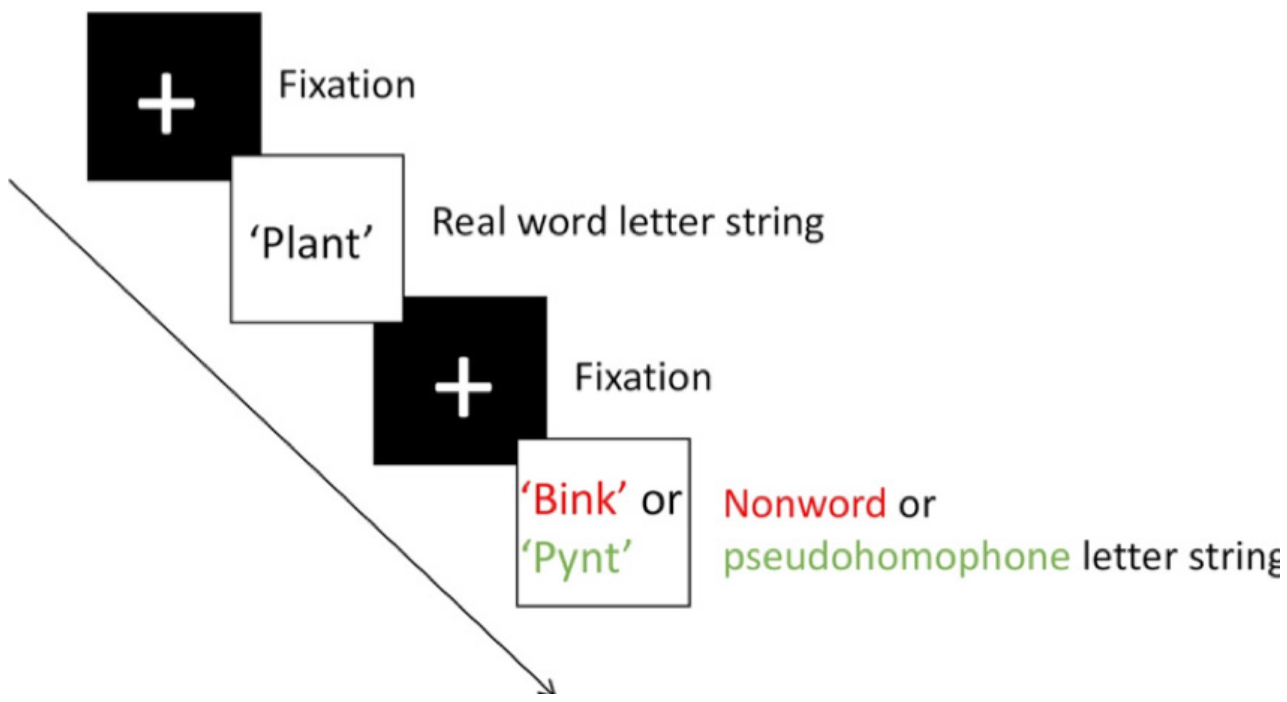

Figure 2. In-scanner (fMRI) response inhibition task procedure. Participants were presented with fixation crosses in between stimulus presentation. There were two different tasks, the nonword task and the pseudohomophone task. The nonword task consisted of presenting real word letter strings (e.g., "plant") and nonword letter strings (e.g., "bink"). The pseudohomophone task consisted of presenting real word letter strings (e.g., "plant") and pseudohomophone letter strings (e.g., "pynt"). Stimulus presentation was randomized in each task; refer to section 2.2 for more details on task procedure.

Sonata scanner and were positioned along each participant's anterior- posterior-commissure line. Anatomical scans included a high-resolution axial T1 MPRAGE sequence with the following parameters: Repetition time $(\mathrm{TR})=2000 \mathrm{~ms}$, Echo Time $(T E)=4.38 \mathrm{~ms}$, number of slices $=144$, base resolution $256 \times 256$, voxel size $1 \times 1 \times 1 \mathrm{~mm}$ scan time 4:48 min. TR and TE are parameters that specify the $\mathrm{fMRI}$ pulse sequence. TR is the repetition time, which is the time from one pulse to the next. TE is echo time-the time between a pulse and data acquisition (Soares et al., 2016). "Pulse" describes the radio frequency magnetic pulse that fMRI uses. EPI stands for echo-planar imaging. This method allows one to obtain images in a short time frame (milliseconds) which minimizes the effects of participant motion (Soares et al. 2016). For each task, 208 volumes of 36 slice, axial spin, EPIs were obtained with the following parameters: TR = $1970 \mathrm{~ms}, \mathrm{TE}=40 \mathrm{~ms}$, base resolution $64 \times 64$ with a $128 \times 128$ reconstruction matrix that improved pixel resolution through zero-filling prior to Fourier transform reconstruction, scan time 6:54 min. EPI slice thickness was $4 \mathrm{~mm}$ with no gap between slices.

\subsection{Data Analysis}

Behavioural Responses

Verbal responses of the participants were analyzed using Audacity (http://audacity.sourceforge. net/), a free software used to manipulate audio files. Noise removal algorithms were implemented to reduce the ambient noise from the magnet. Response time (in milliseconds) was measured as the difference between a visual word onset and the vocal response onset. Correct responses were averaged across trials for each condition and participant. Data were then entered into SPSS for a repeated measures analysis of variance.

\section{Brain Activation}

Step 1. Preprocessing (individual subject level): The first five image volumes were used to achieve a steady state of image contrast and were discarded prior to analysis. The remaining volumes were classified as activity during the task or activity during rest and were subject to standard pre- 
processing using SPM12 (http://www.fil.ion. ucl.ac.uk/spm/). This included: realignment of images from all tasks to each other, slice timing correction within each task, co-registration between the functional and structural images, segmentation of the maps into the tissue probability maps representing grey matter, white matter and cerebral spinal fluid, normalization of the data into a standard brain atlas known as the Montreal Neurological Imaging (MNI) space, and spatial smoothing (averaging part of the signal intensities from neighbouring voxels together) using an $8 \mathrm{~mm}$ full width half maximum kernel.

Step 2. First-level analysis (individual subject level): Data were then entered into a first level analysis using an event-related design and a general linear model approach with six motion parameters as regressors of no interest, which were extracted from the preprocessing step. A general linear model approach is common for statistically analyzing task-based $\mathrm{fMRI}$ investigations (Poline \& Brett, 2012). The model states that $Y=X \beta+\varepsilon$, where $Y$ is the brain signal measured from the fMRI, $X$ is the design matrix, $\beta$ is the standardized regression coefficient, and $\varepsilon$ is the error. Regressors are explanatory variables; by setting the six motion parameters as "regressors of no interest," effects of participant movement are omitted. Estimation of the hemodynamic response function (HRF, a measurement of changes in local blood vasculature that occur following neuronal activity; Soares et al., 2016) was completed using restricted maximum likelihood (ReML) estimation. The activation for each participant and task was thresholded at $p$ < 0.001 with no cluster-size correction (i.e., no correction based on the number of voxels activated).

\section{Step 3. Second-level analysis (group level):}

Second level analysis included averaging data of all participants to create a mean activation map for each condition. Using a one-sample $t$-test, mean activation maps were significant at $t(14)=3.179, p<0.05$ at the group level.

\section{Regions of Interest}

Brain regions of interest that corresponded to response inhibition (anterior cingulate, dorsal medial prefrontal cortex) and reading (inferior frontal gyrus, posterior insula, middle temporal gyrus, middle occipital cortex) were selected for analysis. Then $6 \mathrm{~mm}$ spheres that corresponded with each region were delineated on a standardized $\mathrm{MNI}$ template in Mango (https://www.nitrc.org/projects/ mango/; refer to Figure 3 for specific regions of interest; refer to Table 1 for MNI coordinates). The regions were then entered into SPM12 and analyzed using Mars Bar (https://www.nitrc.org/projects/ marsbar/). Mean percent activation for each region
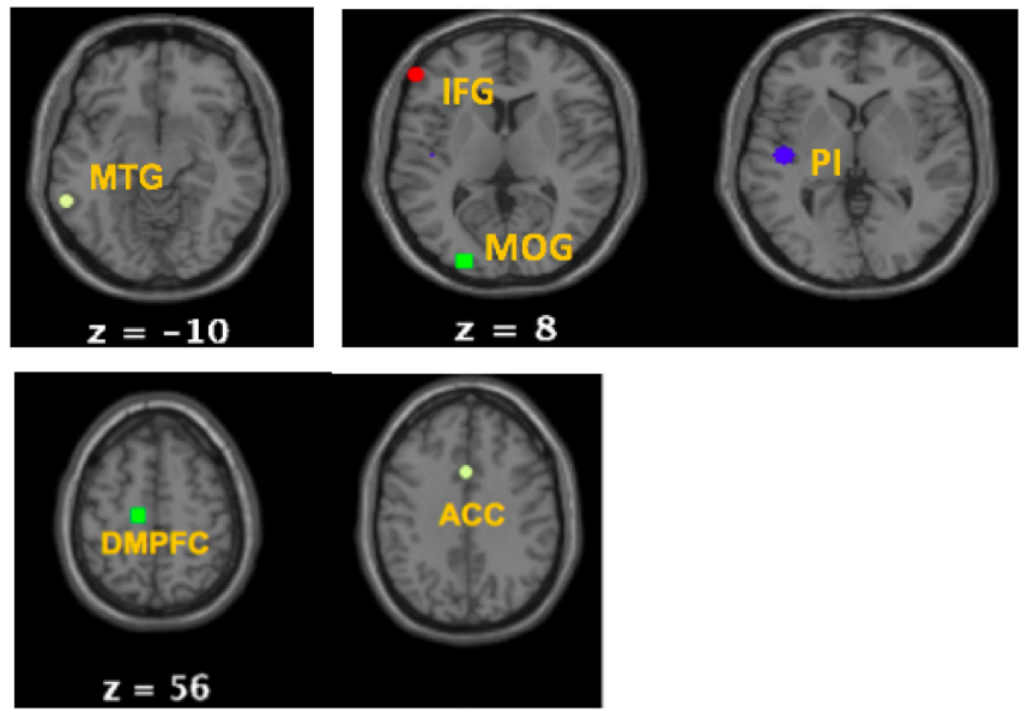

Figure 3. Brain regions analyzed using SPM12 (http://www.fil. ion.ucl.ac.uk/spm/). MTG= Middle Temporal Gyrus; IFG= Inferior Frontal Gyrus; MOG= Middle Occipital Gyrus; $\mathrm{PI}=$ Posterior Insula; DMPFC= Dorsomedial prefrontal cortex; $\mathrm{ACC}=$ Anterior Cingulate Cortex. 
Table 1. Brain regions analyzed (coordinates are in Montreal Neurological Institute space)

\begin{tabular}{|l|l|l|l|l|}
\hline Region Of Interest & $\mathrm{x}$ & $\mathrm{y}$ & $\mathrm{z}$ & Source \\
\hline Anterior Cingulate cortex Middle (ACC) & 0 & 14 & 32 & (Ochsner, Bunge, Gross, \& Gabrieli, 2002) \\
\hline Dorsomedial prefrontal cortex (DMPFC) & -12 & 18 & 54 & (Ochsner et al., 2002) \\
\hline Middle Temporal Gyrus (MTG) & -60 & -46 & -6 & (Rojas et al., 2018) \\
\hline Inferior frontal gyrus (IFG) & -54 & 42 & 12 & (Ochsner et al., 2002) \\
\hline Middle Occipital Gyrus (MOG) & -24 & -92 & 10 & (Rojas et al., 2018) \\
\hline Posterior insula (PI) & -44 & -16 & 2 & (Ochsner et al., 2002) \\
\hline
\end{tabular}

was collected and then entered into SPSS (www. ibm.com/DataStatistics/SPSS) for statistical analysis. In SPSS, paired sample $t$-tests were used to compare: nonwords (NWs) to words (in the NW foil); PHPs to words (in the PHP foil); NWs to PHPs; words (in the NWs foil) to words (in the PHP foil).

\section{Results}

3.1 Behavioural Results:

Table 2 shows that response time to name words in the PHP task was slower than the response time to name words in the NW task. This difference was statistically significant $(p=0.042)$.

Table 2. Mean reaction times in milliseconds ( $\mathrm{ms}$ ) (standard deviation) and accuracy (\%)

\begin{tabular}{|l|l|l|}
\hline Condition & $\begin{array}{l}\text { Reaction Time } \\
(\mathrm{ms})\end{array}$ & $\begin{array}{l}\text { Accuracy } \\
(\%)\end{array}$ \\
\hline Nonword Foils & $752.5(105.1)$ & $95.4(2.7)$ \\
\hline $\begin{array}{l}\text { Pseudohomophone } \\
\text { Foils }\end{array}$ & $910.0(248.0)$ & $96.2(3.4)$ \\
\hline
\end{tabular}

Table 3. Paired samples t-test for activation during nonwords (NWs) compared to words (in the NW foil). *significant difference at $p<0.05$.

\begin{tabular}{|l|l|l|l|}
\hline $\begin{array}{l}\text { Region of } \\
\text { Interest }\end{array}$ & Mean diff. & df & $\begin{array}{l}\text { Sig. } \\
(2 \text {-tailed })\end{array}$ \\
\hline ACC & -0.06279 & 13 & 0.060 \\
\hline DMPFC* & -0.04080 & 14 & 0.010 \\
\hline $\mathrm{PI}^{\star}$ & -0.1086 & 13 & 0.000 \\
\hline
\end{tabular}

\section{2 fMRI Results:}

Anterior Cingulate Cortex (ACC):

A difference in mean percent activation for NWs compared to words (in the NW foil) approached significance $(p=0.060)$. A significant difference in mean percent activation for PHPs compared to words (in the PHP foil; $p=0.034$ ) was found (refer to Table 3 \& 4; Figure 4).

\section{Dorsomedial prefrontal cortex (DMPFC):}

A significant difference in mean percent activation for NWs compared to words (in the NW foil) $(p=0.034)$ was found (refer to Table 2; Figure 4).

Middle Temporal Gyrus (MTG):

A significant difference in mean percent activation for PHPs compared to words (in the PHP foil) $(p=0.013)$ was found (refer to Table 3; Figure 4).

Inferior frontal gyrus (IFG):

No significant differences were found between the stimuli. High mean percent activation was found for the words (in the NW foil), the PHPs, and the words (in the PHP foil). In contrast, low mean

Table 4. Paired samples t-test for activation during pseudohomophones (PHPs) compared to words (in the PHP foil). *significant difference at $\mathrm{p}<0.05$.

\begin{tabular}{|l|l|l|l|}
\hline $\begin{array}{l}\text { Region of } \\
\text { Interest }\end{array}$ & Mean diff. & df & $\begin{array}{l}\text { Sig. } \\
\text { (2-tailed) }\end{array}$ \\
\hline ACC* & -0.06479 & 13 & 0.034 \\
\hline MTG* $^{*}$ & -0.04267 & 14 & 0.013 \\
\hline PI* $^{*}$ & -0.07607 & 13 & 0.011 \\
\hline
\end{tabular}


percent activation was found in the NWs (Figure 4).

Middle Occipital Gyrus (MOG):

No significant differences were found between the stimuli. High mean percent activation was found across all tasks; NWs, the words (in the NW foil), the PHPS, and the words (in the PHP foil; Figure 4).

Posterior insula (PI):

A significant difference in mean percent activation for NWs compared to words (in the NW foil) ( $p<$ 0.001) and PHPs compared to words (in the PHP foil; $p=0.011$ ) was found (refer to Table 2 \& 3; Figure 4).

\section{Discussion}

The purpose of the present work was to explore the extent to which brain regions associated with decision-making processes are differentially active during reading tasks that vary in difficulty of response inhibition. Here, we found evidence for differential activation in brain regions associated with decision-making processes (ACC), error detection (DMPFC) and semantic processing (MTG). Equally valuable, we provide additional information on brain regions that were not sensitive to complex decision-making per se, but instead reflect differences in more general language function. These findings are discussed in further detail below.

\subsection{Task Complexity}

As previously outlined, assessing the spelling of real words relies on the retrieval of information that is already known (lexical processes; refer to 1.2) and relatively quick to access. In the NW task, rejection of NWs is also relatively straightforward as the decoding process does not lead to any familiar print (i.e. written words) or sound information. In contrast, assessing the spelling of PHPs produces unfamiliar print but familiar sound information, making this task more complex than the NW task. Our behavioural

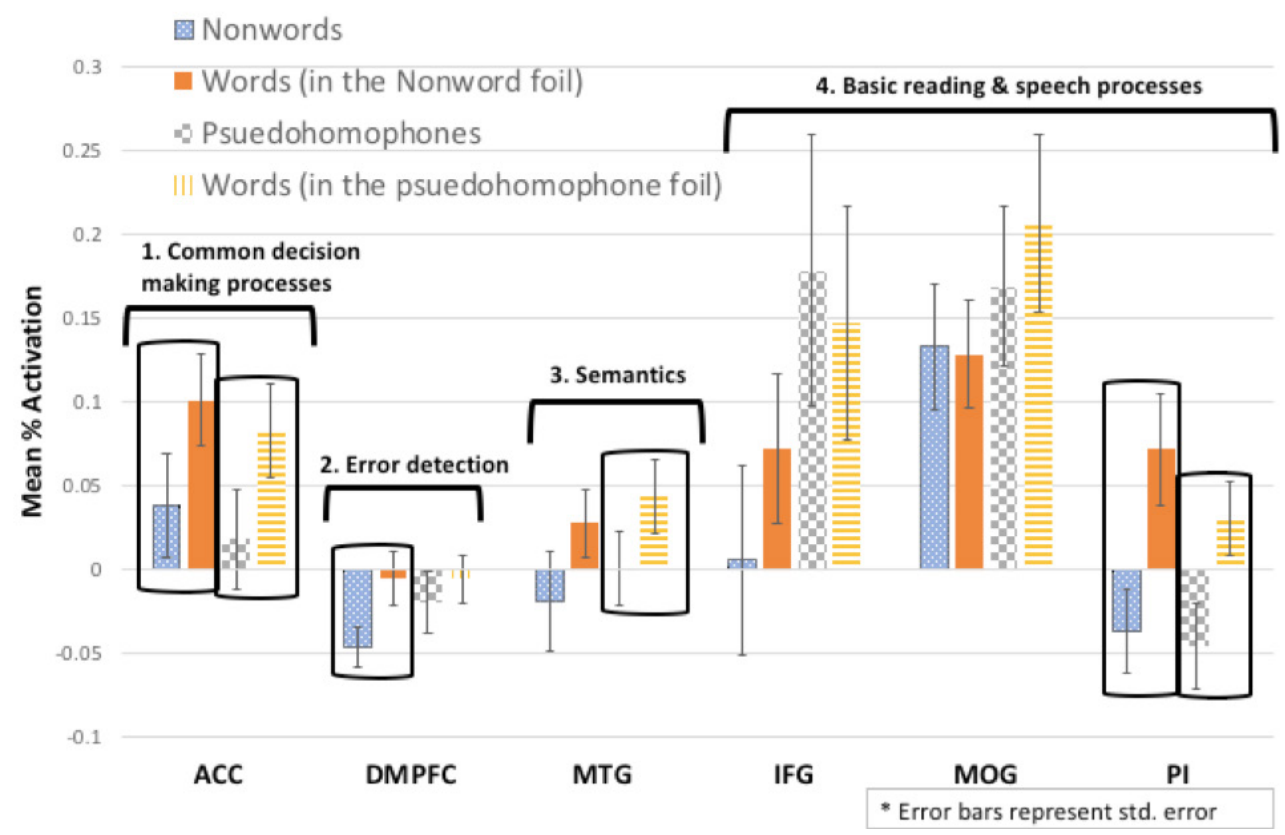

Figure 4. Brain activation of participants while engaged in response inhibition reading tasks.

The bars represent mean percent activation for different types of words: nonwords (dots); pseudohomophones (solid); words within the nonword task (checkered); words within the pseudohomophone task (striped). The black boxes indicate significant differences in activation from performed t-tests (refer to Table 3 \& 4). The brackets indicate the function of that brain region in reading tasks (e.g., the ACC is important for common decision-making processes). Outliers $>2.5 \mathrm{std}$. dev. were assessed and removed on a region by region basis (from each of the IFG, MOFC, $\mathrm{PI}$, and $\mathrm{ACC}$ ). 
data supports the notion that the PHP task is indeed more complex, as the PHP task led to significantly longer reaction times in participants than the NW task. Ultimately, individuals needed to resolve the conflicting no-go (print information) and go (sound information) information to complete the task successfully, and this required additional time.

\subsection{Common decision-making processes: Anterior Cingulate Cortex (ACC)}

The ACC regulates decision-making, specifically in situations that require response override (Botvinick, 2007). An example of response override is incongruent trials of the stroop task- a common task in psychology where one must override saying the colour a letter string spells and instead say the colour of the letter string. The difference in activation of the ACC for nonwords compared to words in the nonword foil approached significance and was significant for PHPs compared to words in the PHP foil. Specifically, the NWs and PHPS showed a smaller mean percent activation than the words. Recall that the task required responses for NWs and PHPs to be withheld and responses for words to be said aloud. Therefore, this finding indicates that activation of the ACC was greater when overt response was required for the task. This supports the idea that the ACC was involved in deciding which stimuli to inhibit a response for and which stimuli to allow a response for, affirming the ACC's role in response inhibition decisions. 4.3 Error detection: Dorsomedial Prefrontal Cortex (DMPFC)

Researchers have shown the DMPFC to be critical for error detection during decision-making (Holroyd et al., 2005; Modirrousta \& Fellows, 2008). Greater negative activation (i.e., greater inhibition) of the DMPFC for NWs compared to words may indicate that NWs are detected as errors in this condition (i.e., they were unfamiliar; when an intermittent nonword was presented amidst the real words, the unfamiliar word was detected as an error). In contrast, the lack of difference in activation between PHPs and real words may indicate that the familiar sounds associated with PHPs (i.e., they sound like a real word) were not detected as an error. Thus, it is likely that two different strategies were employed for the NW task versus the PHP task. The less complex NW task used automatic evaluation of words encoded in memory to determine if a word was familiar or not. If the letter string was familiar, a response was permitted, whereas, if the letter string was unfamiliar, the response was inhibited. In contrast, the more complex PHP task required evaluation of the stimulus via grapheme to phoneme decoding, in order to recognize that the PHP was not a real word. As such, it was not automatically coded as an error. In line with this notion, the PHP task had less negative activation (a smaller inhibitory response), indicating it was not automatically coded as an error.

4.4 Semantic: Middle Temporal Gyrus (MTG)

Researchers have shown the MTG to be implicated in semantic control (Davey et al., 2016). Spelling automatically activates familiar sounds and, subsequently, the semantics associated with words. Greater positive mean activation for words, compared to NWs and/or PHPs in each condition, indicates that words activated regions associated with meaning. In contrast, negative activation of the NWs is in line with the fact that these stimuli have no semantics associated with them. Similarly, the PHPs had little activation, indicating that access to meaning was not immediately available. This makes sense as the PHPs need to be sounded out, and only once the familiar sound has been generated, can the PHP be recognized as a word. After these steps, activation of semantics likely ensues.

4.5 Basic reading and speech processes: IFG, MOG, $\& P I$

Inferior Frontal Gyrus (IFG): High activation of the IFG for real words and PHPs (familiar phonemes), but not for nonwords, supports other researchers' findings that the IFG plays a role in phonological 
processing (Burton, 2001) and storing familiar speech sounds (Guenther, 2006). The relatively higher mean percentage activation for PHPs compared to real words may be indicative of the greater effortful decoding of each speech sound that accompanies reading of PHPs. Further to this point, the NW stimuli produced very weak activation in the IFG. Given that the NWs were legal English letter strings, and thus contained familiar phonemes and biphones, the portion of the IFG isolated in this study is likely particularly sensitive to word level phonology, which the NWs lacked.

Middle Occipital Gyrus (MOG): High activation of the left MOG for all reading tasks supports other researcher's findings that it is implicated in visual word form processing (Vorobyev et al., 2004). Visual word form processing includes the identification of shapes, letters, and words prior to, or in parallel to, identification of sound and/or meaning (Dehaene \& Cohen, 2011). Visual word form processing is critical for reading as evidenced by the high mean percentage activation of the MOG across each task and for each stimulus type.

Posterior Insula (PI): While previous work has implicated the anterior insula in speech and articulatory production (Oh, Duerden, \& Pang, 2014), the role of the posterior insula in reading processes is less understood. Here we found significant negative activation in the $\mathrm{PI}$ for NWs compared to words in the NW foil, and PHPs compared to words in the PHP foil. This provides some evidence that the PI may be involved in inhibition and articulatory control during reading tasks that require decisionmaking. The high positive activation found for words in both the NW and PHP foil, where articulation was required, provides additional evidence for this notion. Together, this pattern of brain activation suggests the $\mathrm{PI}$ is sensitive to the go/no-go aspect of the task procedure used in this study.
4.6 General Discussion: Beyond Basic Word Recognition

While the work shown here provides some insight into the role that executive function skills may play in the identification and speed of processing in basic reading tasks, we need to consider the bigger picture. Specifically, these basic reading skills are required to build a foundation for complex reading comprehension (Mahone et al., 2002). Reading comprehension ability is vital for success in higher level academics and professions, and deficits have a large impact on individuals' lives. Approximately $10-25 \%$ of those with reading impairments attain normal word recognition scores, yet still struggle with comprehension (Lacascio, Mahone, Eason, \& Cutting, 2010). These individuals are classified as having a specific reading comprehension deficit (S-RCD) due to impaired executive function.

Executive dysfunction-dysfunction of motor response inhibition, working memory, and planningis characteristic of attention-deficit/hyperactivity disorder (ADHD) (Songuga-Barke, Sergeant, Nigg, \& Willcutt, 2008). In fact, impaired response inhibition has even been suggested to be a potential indicator of ADHD (Castellanos \& Tannock, 2002). Children with ADHD without word recognition impairment, are often described by researchers as having word comprehension impairment due to executive dysfunction (Brock \& Knapp, 1996; Mclnnes, Humphries, Hogg-Johnson, \& Tannock, 2003). Such findings have led to the proposal that response inhibition training could potentially be used to assist individuals with executive dysfunction difficulties. Response inhibition training has yet to be explored in the context of treatment for people with reading comprehension deficits, but has been used in several contexts unrelated to reading (i.e., altering compulsive behaviour: gambling, Stevens et al., 2015; alcohol addiction, Houben, Nederkoorn, Wiers, \& Jansen, 2011; overconsumption of food, Veling, van Koningsbruggen, Aarts, \& Stoebe, 2014). The work outlined in this paper provides a first step towards understanding 
whether response inhibition reading tasks could potentially be used as a rehabilitative tool for individuals with reading comprehension deficits.

\section{Conclusion}

Activation of various brain regions during response inhibition reading tasks that vary in level of complexity were investigated. We found that response inhibition reading tasks do engage regions of the decision-making network, namely, the Anterior Cingulate Cortex (ACC), Dorsomedial Prefrontal Cortex (DMPFC), Middle Temporal Gyrus (MTG), Inferior Frontal Gyrus (IFG), Middle Occipital Gyrus (MOG), and Posterior Insula (PI). The PHP task took participants significantly longer to complete than the NW task, supporting the notion that the PHP task was more complex. Common activation for NWs and PHPs occurred in the PI and ACC. These results support the PI's role in articulatory control (both go and nogo) and the ACC's role in decision-making. The DMPFC was found to be significantly activated only for the NW task, suggesting two different strategies were employed for completing the NW and PHP task. Significant activation of the MTG occurred for PHPs, supporting the MTG's role in semantic processing. High activation of the IFG for PHPs and words supports its role in word level phonological processing. Finally, high activation of the MOG for all tasks supports its involvement in visual word form processing.

\section{Limitations and Future Directions}

While the current study purposefully constrained the examination of brain regions to a small number of regions of interest (ROI), decisionmaking processes are ultimately complex and likely include many regions not studied here. In addition, the interactions between, and among, these regions are necessary to fully understand the dynamic nature of response inhibition as it unfolds during the reading process. Similarly, investigating the extent to which the findings here generalize to a range of reading abilities and executive functioning abilities is warranted, as the sample included in the current study was restricted and small. This research could potentially inform the origin of impairment for readers with executive dysfunction. In addition, a longitudinal study on response inhibition training would be required to make more definitive statements about readers with executive dysfunction. This would indicate whether their ability to perform response inhibition reading tasks, and their subsequent neural activation in regions responsible for response inhibition, improves with practice. 


\section{Appendix}

Response inhibition task wordlist

\begin{tabular}{|c|c|c|c|c|c|c|c|}
\hline Range & won & heard & move & bull & pohr & bawss & doun \\
\hline fraud & doce & threet & tov & heer & burp & stick & bath \\
\hline tomb & glove & swear & meent & bound & scarce & gess & womb \\
\hline besh & crow & earth & land & scent & glyde & soup & twice \\
\hline cost & stroll & glow & olf & same & psalm & mouth & hahnd \\
\hline creek & brief & which & ranch & wel & wool & sweep & fleet \\
\hline throat & thrust & steam & trance & freak & fule & aunt & \\
\hline barb & brodge & per & steak & host & bare & stead & \\
\hline toin & claim & while & flow & chart & risk & heet & \\
\hline seg & charm & swean & lose & dost & hoal & nyne & \\
\hline says & bright & spread & moive & comb & flame & shriek & \\
\hline grov & woald & must & whom & sag & vogue & dark & \\
\hline truce & down & mulch & path & ledj & green & prime & \\
\hline cime & brooch & breek & trap & whood & roll & stawck & \\
\hline yoarn & hold & scale & sense & whyle & tree & nerve & \\
\hline view & binch & whece & swoap & musst & lawss & pyne & \\
\hline pint & yeast & plague & norve & mow & shed & bunch & \\
\hline triat & foot & youn & breit & worm & sez & gone & \\
\hline front & launch & cliff & seb & toast & lunch & trough & \\
\hline stock & pusk & mov & heat & sweat & $\operatorname{siv}$ & one & \\
\hline tough & frant & flash & flane & ease & hood & south & \\
\hline caste & breest & house & savs & flute & leave & broach & \\
\hline vose & trial & threab & grew & faith & prufe & pull & \\
\hline sheb & sainf & snow & do & lahnd & dawdge & tue & \\
\hline shove & priest & mist & match & work & cross & ghoul & \\
\hline stern & darf & sare & breast & bowl & tuf & graph & \\
\hline bridge & hoot & soite & dohr & crowd & suede & mount & \\
\hline post & wape & wisp & buhlk & tin & touch & will & \\
\hline whoce & shoa & swathe & had & gaze & mintz & pohrk & \\
\hline dole & grind & meant & death & clash & hite & yearn & \\
\hline whole & sour & glide & staff & tun & plaid & pause & \\
\hline guide & count & drawer & stow & duz & wage & wich & \\
\hline sieve & tronce & sparse & jaunt & hence & breaf & court & \\
\hline none & gross & blink & dress & couch & hooht & crepe & \\
\hline grev & height & door & style & grouch & blow & doh & \\
\hline truth & welf & brair & breth & gihv & plain & wunce & \\
\hline short & easc & free & four & pope & most & vase & \\
\hline cust & push & coush & tryal & stack & monk & done & \\
\hline crook & storm & with & breatch & ern & taste & thret & \\
\hline toask & pork & board & glahnd & showt & some & head & \\
\hline dearth & saint & wipe & haunt & off & steel & frea & \\
\hline pem & mind & soize & sware & hook & saynt & yor & \\
\hline
\end{tabular}




\section{Notes}

1. Although the dual route model is used as a framework in the current paper, there are additional reading models that could also provide a framework from which we could investigate the response inhibition processes, namely parallel distributed process models (PDP). PDP models describe the interaction of units of information (orthographic, phonological, and semantic) that are capable of deriving an appropriate response for various reading tasks (Plaut, McClelland, Seidenberg, \& Patterson 1996; Harm \& Seidenberg, 2004). While a framing of the present research questions/hypotheses in the context of the PDP models is beyond the scope of the current work, such an endeavour is a necessary one for future studies. 


\section{References}

Balota, D.A., Yap, M.J., Hutchison, K.A., Cortese, M.J., Kessler, B., Loftis, B., Neely, J.H., Nelson, D.L., Simpson, G.B., Treiman, R. (2007). The english lexicon project. Behavior Research Methods, 39, 445-459. https://doi.org/10.3758/BF03193014

Aron, A.R. \& Poldrack, R.A. (2005). The cognitive neurosciences of response inhibition: Relevance for genetic research in attention-deficit/hyperactivity disorder. Biological Psychiatry, 57(11), 12851292. https://doi.org/10.1016/j.biopsych.2004.10.026

Botvinick, M.M. (2007). Conflict monitoring and decision making: reconciling two perspectives on anterior cingulate function. Cognitive, Affective, \& Behavioral Neuroscience, 7, 356-366. https:// doi.org/10.3758/CABN.7.4.356

Brock, S.E. \& Knapp, P.K. (1996). Reading comprehension abilities of children with AttentionDeficit/Hyperactivity Disorder. Journal of Attention Disorder, 1, 173-185. https://doi. org/10.1177/108705479600100305

Burton M.W. (2001). The role of the inferior frontal cortex in phonological processing. Cognitive Sciences, 25, 695-709. https://doi.org/10.1207/s15516709cog2505_4

Castellanos, F.X. \& Tannock, R. (2002). Neuroscience of attention-deficit/hyperactivity disorder: The search for endophenotypes. Nature Reviews: Neuroscience, 3, 617-628. https://doi.org/10.1038/ $\underline{\text { nrn896 }}$

Coltheart, M., Rastle, K., Perry, C., Langdon, R., \& Ziegler, J. (2001). DRC: A dual route cascaded model of visual word recognition and reading aloud. Psychological Review, 108(1), 204-256. https://doi. org/10.1037/0033-295x.108.1.204

Cummine, J., Amyotte, J., Pancheshen, B., \& Chouinard, B. (2011). Evidence for the modulation of sublexical processing in go no-go naming: The elimination of the frequency $\times$ regularity interaction. Journal of Psycholinguistic Research, 40(5-6), 367-378. https://doi.org/10.1007/s10936-0119174-2.

Cummine, J., Gould, L., Zhou, C., Hrybouski, S., Siddiqi, Z., Chouinard, B., \& Borowsky, R. (2013). Manipulating instructions strategically affects reliance on the ventral-lexical reading stream: Converging evidence from neuroimaging and reaction time. Brain and Language, 125(2), 203-214. https://doi.org/10.1016/j.bandl.2012.04.009.

Cummine, J., Aalto, D., Ostevik, A., Cheema, K., \& Hodgetts, W. (2018). "To name or not to name: that is the question": The role of response inhibition in reading. Journal of Psycholinguistic Research, 47(5), 999-1014. https://doi.org/10.1007/s10936-018-9572-9

Davey, J., Thompson, H.E., Hallam, G., Karapanagiotidis, T., Murphy, C., De Caso, I., Krieger-Redwood, K., Bernhardt, B.C., Smallwood, J., \& Jefferies, E. (2016). Exploring the role of the posterior middle 
temporal gyrus in semantic cognition: Integration of anterior temporal lobe with executive processes. Neurolmage, 137, 165-177. https://doi.org/10.1016/j.neuroimage.2016.05.051

Dehaene, S. \& Cohen, L. (2011). The unique role of the visual word form area in reading. Trends in Cognitive Sciences, 15(6), 254-262.https://doi.org/10.1016/j.tics.2011.04.003

Holroyd, C.B., Yeung, N., Coles, M.G., \& Cohen J.D . (2005). A mechanism for error detection in speeded response time tasks. Journal of Experimental Psychology: General, 134, 163-191. https://doi. org/10.1037/0096-3445.134.2.163

Harm, M.W., \& Seidenberg, M.S. (2004). Computing the meanings of words in reading: Cooperative division of labor between visual and phonological processes. Psychological Review, 111(3), 662720. https://doi.org/10.1037/0033-295X.111.3.662

Hino, Y., \& Lupker, S. J. (1998). The effects of word frequency for Japanese Kana and Kanji words in naming and lexical decision: Can the dual-route model save the lexical-selection account? Journal of Experimental Psychology: Human Perception and Performance, 24(5), 1431-1453. https://doi.org/10.1037/0096-1523.24.5.1431.

Hino, Y., \& Lupker, S. J. (2000). Effects of word frequency and spelling-to-sound regularity in naming with and without preceding lexical decision. Journal of Experimental Psychology: Human Perception and Performance, 26(1), 166-183. https://doi.org/10.1037/0096-1523.26.1.166.

Houben, K., Nederkoorn, C., Wiers, R.W., \& Jansen, A. (2011). Resisting temptation: decreasing alcohol-related affect and drinking behavior by training response inhibition. Drug and Alcohol Dependence, 116 (1-3), 132-136. https://doi.org/10.1016/j.drugalcdep.2010.12.011

Kahneman, D. (2003). A perspective in judgment and choice: Mapping bounded rationality. American Psychologist, 58, 697-720. http://dx.doi.org/10.1037/0003-066X.58.9.697

Lacascio, G., Mahone, E.M., Eason, S.H., \& Cutting, L.E. (2010). Executive dysfunction among children with reading comprehension deficits. Journal of Learning Disabilities, 43(5), 441-454. https:// dx.doi.org/10.1177\%2F0022219409355476

Li, C.R., Huang, C., Constable, R.T., \& Sinha, R. (2006). Imaging Response Inhibition in a stop-signal task: neural correlates independent of signal monitoring and post-response processing. Journal of Neuroscience, 26(1), 186-192. https://doi.org/10.1523/JNEUROSCI.3741-05.2006

Mahone, E.M., Hagelthorn, K.M., Cutting, L.E., Schuerholz, L.J., Pelletier, S.F., Rawlins, C., Singer, H.S., \& Denckla, M.B. (2002). Effects of IQ on executive function measures in children with ADHD. Child Neuropsychology, 8(1), 52-65.https://doi.org/10.1076/chin.8.1.52.8719

Mclnnes, A., Humphries, T., Hogg-Johnson, S., \& Tannock, R. (2003). Listening comprehension and working memory are impaired in attention-deficit hyperactivity disorder irrespective of language impairment. Journal of Abnormal Child Psychology, 31(4), 427-43. https://doi. org/10.1023/A:1023895602957 
Modirrousta, M., \& Fellows, L.K. (2008). Dorsal medial prefrontal cortex plays a necessary role in rapid error prediction in humans. Journal of Neuroscience, 28(51), 14000-14005. https://doi. org/10.1523/JNEUROSCI.4450-08.2008

Ochsner, K.N., Bunge, S.A., Gross, J.J., \& Gabrieli, J.D.E. (2002). Rethinking feelings: An fMRI study of the cognitive regulation of emotion. Journal of Cognitive Neuroscience, 14(8), 1215-1229. https://doi. org/10.1162/089892902760807212

Oh, A., Duerden E.G., \& Pang E.W. (2014). The role of the insula in speech and language processing. Brain and Language, 135, 96-103. https://doi.org/10.1016/j.bandl.2014.06.003

Plaut, D. C., McClelland, J. L., Seidenberg, M. S., \& Patterson, K. (1996). Understanding normal and impaired word reading: Computational principles in quasi-regular domains. Psychological Review, 103(1), 56-115. http://dx.doi.org/10.1037/0033-295X.103.1.56

Poline J.B., \& Brett, M. (2012). The general linear model and fMRI: does love last forever? Neurolmage, 62, 871-880. https://doi.org/10.1016/j.neuroimage.2012.01.133

Rojas, G. M., Alvarez, C., Montoya, C. E., de la Iglesia-Vayá, M., Cisternas, J. E., \& Gálvez, M. (2018). Study of Resting-State Functional Connectivity Networks Using EEG Electrodes Position as Seed. Frontiers in Neuroscience, 12, 235. https://doi.org/10.3389/fnins.2018.00235

Soares, J. M., Magalhães, R., Moreira, P. S., Sousa, A., Ganz, E., Sampaio, A., Alves, V., Marques, P., \& Sousa, N. (2016). A Hitchhiker's Guide to Functional Magnetic Resonance Imaging. Frontiers in Neuroscience, 10, 515.https://doi.org/10.3389/fnins.2016.00515

Sonuga-Barke, E.J.S., Sergeant, J.A., Nigg, J., \& Willcutt, E. (2008). Executive dysfunction and delay aversion in attention deficit hyperactivity disorder: Nosologic and diagnostic implications. Child and Adolescent Psychiatric Clinics of North America, 17(2), 367-384. https://doi.org/10.1016/j. chc. 2007.11 .008

Stevens, T., Brevers, D., Chambers, C. D., Lavric, A., McLauren, I. P. L., Mertens, M., Noël, X., \& Verbruggen, F. (2015). How does response inhibition influence decision making when gambling? Journal of Experimental Psychology: Applied, 21(1), 15-36. http://dx.doi.org/10.1037/xap0000039

Veling, H., van Konnigsbruggen, G. M., Aarts, H., \& Stroebe, W. (2014). Targeting impulsive processes of eating behavior via the Internet: Effects on body weight. Appetite, 78, 102-109. https://doi. org/10.1016/j.appet.2014.03.014

Vorobyev, V.A., Alho, K., Medvedev, S.V., Pakhomov, S.V., Roudas, M.S., Rutkovskaya, J.M., Tervaniemi, M., van Zuijen, T.L., \& Naatanen, R. (2004). Linguistic processing in visual and modality-nonspecific brain areas: PET recordings during selective attention. Cognitive Brain Research, 20(2): 309-322. https://doi.org/10.1016/j.cogbrainres.2004.03.011 